\title{
MORFOLOGIA DE FRUTOS, SEMENTES, PLÂNTULAS E PLANTAS DE Erythrina velutina WILLD., LEGUMINOSEAE - PAPILIONIDEAE ${ }^{1}$
}

\author{
KELINA BERNARDO SILVA ${ }^{1}$, EDNA URSULINO ALVES², RISELANE DE LUCENA ALCÂNTARA BRUNO², \\ VALDEREZ PONTES MATOS ${ }^{3}$, EDILMA PEREIRA GONÇALVES ${ }^{3}$
}

\begin{abstract}
RESUMO - O conhecimento dos aspectos morfológicos de sementes e plântulas pode ser usado em estudos de taxonomia, na interpretação de testes de germinação em laboratório, trabalhos em viveiro e em estudos relacionados à ecologia da espécie. Os objetivos deste trabalho foram o de descrever e ilustrar a morfologia externa e interna dos frutos e sementes, as fases de germinação, a plântula e as plantas de mulungu (Erythrina velutina Willd.). Os frutos e sementes foram coletados no solo, embaixo de árvores matrizes distribuídas em diferentes fragmentos florestais, no município de Areia - PB. Para a descrição morfológica dos frutos, sementes, germinação e desenvolvimento da plântula foram examinados cem unidades que foram selecionadas aleatoriamente. A semente é reniforme; embrião axial com cotilédones carnosos; germinação epígea fanerocotiledonar e na fase de plântula foi observado heterofilia. Os aspectos descritos e ilustrados mostraram-se homogêneos e confiáveis para a identificação da espécie. Deste modo, podem ser úteis em trabalhos de tecnologia de sementes, para a avaliação qualidade fisiológica de sementes e avaliação de plântulas em testes de germinação, além de servirem para identificação da espécie em viveiros e também para estudos de regeneração natural.
\end{abstract}

Termos para indexação: mulungu, morfologia, sementes, plântulas, medicinal.

\section{MORPHOLOGY OF FRUITS, SEEDS AND SEEDLINGS OF Erythrina velutina WILLD., LEGUMINOSEAE - PAPILIONIDEAE}

\begin{abstract}
The knowledge about the morphological aspects of both seeds and seedlings has several applications, such as in taxonomy, interpretation of the germination tests under laboratory conditions, in nurseries, as well as in ecological studies. Therefore, the goals of this work were to describe and illustrated both internal and external morphologies of the fruits and seeds as well as the germination phases and seedling development of mulungu (Erythrina velutina Willd.). The fruits and seeds were collected in the soil, which were dispersed by trees distributed throughout different forest fragments in the district of Areia in the State of Paraiba, Brazil. One hundred units were randomly selected for the morphological description of the fruits, seeds and germination phases. The results showed that the seed was reniform; had axial embryo with pulpous cotyledons; epigeal phanerocotylar and showed the presence of heterophylly at the seedlings phases. The described and illustrated aspects
\end{abstract}

${ }^{1}$ Submetido em 03/09/2007. Aceito em 13/08/2008.

${ }^{1}$ Doutoranda do Curso de Agronomia do Centro de Ciências Agrárias da Universidade Federal da Paraíba, Areia-PB, e-mail:kelinabernado@yahoo.com.br

${ }^{2}$ Profa. Dra. do Depto. de Fitotecnia do Centro de Ciências Agrárias da
Universidade Federal da Paraíba, Areia-PB,

${ }^{3}$ Profa. Dra. da Universidade Federal Rural de Pernambuco, Departamento de Agronomia, Área de Fitotecnia. 
were homogeneous and reliable for the identification of the species. Thus, the results are useful in the technological work for evaluation of the physiological quality of the seeds as well as for evaluation of seedling morphology during germination tests. In addition, the results are useful for identification of the species in nurseries and in natural regeneration studies.

Index terms: mulungu, medicinal, forest, germination, seed structure

\section{INTRODUÇÃO}

Para garantir a sobrevivência, as espécies vegetais desenvolveram em suas sementes grande variedade de estruturas de dispersão, implicando em maior ou menor sucesso desta no ambiente (Russel e Musil, 1969). Segundo Gunn (1981), tanto as características externas quanto as internas das sementes são pouco modificadas pelo ambiente, constituindo-se assim, em variáveis seguras para uso na identificação de espécies. Sementes das diferentes espécies apresentam variação de tamanho, forma, coloração e aspecto superficial (Beltrati, 1992). As principais características externas empregadas em estudos morfológicos são a forma, a coloração, a presença de cicatrizes ou apêndices, enquanto as internas são tipo, forma, tamanho e localização do embrião, quantidade e qualidade do material de reserva (Gunn, 1981). O grau de confiabilidade dos caracteres morfológicos para identificação é dado pela sua constância, de modo que, quanto mais constantes se apresentarem maior será a sua confiabilidade (Kuniyoshi, 1983).

As sementes têm características básicas para a identificação de famílias ou até mesmo do gênero, espécie ou variedade à qual a planta pertence. Nesse sentido, Donadio e Demattê (2000a) relataram que na Botânica Sistemática, somente os caracteres de planta adulta são freqüentemente utilizados, enquanto as características das plântulas são pouco utilizadas, talvez pela limitação de dados e ausência de tradição. Dessa forma, o conhecimento das estruturas morfológicas dos frutos, sementes e plântulas florestais é importante para diversos fins como: nos laboratórios de análise de sementes, na identificação e na diferenciação de espécies, no reconhecimento da planta no campo, na taxonomia e na silvicultura (Amorim et al., 1997). Estudos morfológicos de sementes e plântulas são importantes para facilitar pesquisas sobre banco de sementes do solo, bem como para auxiliar na identificação de espécies em estudos de regeneração natural de áreas degradadas (Araújo Neto et al., 2002).

$\mathrm{O}$ fruto e a semente podem fornecer indicações sobre o tipo de armazenamento, viabilidade e métodos de semeadura
(Kuniyoshi, 1983), podendo contribuir para uma correta interpretação dos testes de germinação (Araújo e Matos, 1991), auxiliar na compreensão da dinâmica de populações vegetais, bem como, no reconhecimento do estágio sucessional em que a floresta se encontra (Oliveira, 1993; Donadio e Demattê, 2000a).

No que diz respeito às sementes, de modo geral, os caracteres internos são de interesse na classificação, tendo importância particular à presença ou ausência de endosperma, forma e posição do embrião, número e posição dos cotilédones (Lawrence, 1973). As características morfológicas das plântulas, à semelhança das sementes, também permitem a identificação de famílias, gêneros e até espécies (Oliveira, 1993), a autora acrescentou ainda que estas características têm sido bastante empregadas em estudos de inventário, tanto nas regiões temperadas quanto nas regiões tropicais. Estudos sobre o desenvolvimento de plântulas propiciam a separação de espécies muito semelhantes no viveiro, assim como pode ser úteis em estudos de regeneração natural (Kuniyoshi, 1983), bem como podem ser usadas para melhor compreender a estrutura e a dinâmica dos ecossistemas naturais e ainda para auxiliar na definição de estratégia para recuperação de áreas degradadas (Soriano e Torres, 1995).

A observação do desenvolvimento da plântula permite diferenciar grupos taxonômicos muito semelhantes entre si, bem como auxiliar nos estudos de regeneração e nos trabalhos de tecnologia de sementes, como testes diretos e indiretos para avaliação da germinação e vigor das sementes, além do reconhecimento das espécies em viveiros de produção de mudas (Pereira, 1988), embora as plântulas de espécies e gêneros afins apresentem características morfológicas externas semelhantes tornando a identificação imprecisa e, às vezes, até impossível (Pinheiro et al., 1990).

Estudos que visam o conhecimento da morfologia de frutos, sementes, plântulas e plantas de espécies arbóreas são ainda escassos na literatura referencial, tendo como exemplos os trabalhos de Melo et al. (2004) com Hymenaea intermedia Ducke var. adenotricha (Ducke) Lee \& Lang., Matheus e Lopes (2007) com Erythrina variegata L., Melo et 
al. (2007) com Protium Burm. f., Rodrigues e Tozzi (2007) com Bowdichia virgilioides Kunth, Vidigal et al. (2007) com Azadirachta indica A. Juss., Paiva Sobrinho e Siqueira (2008) com Guazuma ulmifolia Lam.

As características morfológicas de frutos, sementes e plântulas de E. velutina (Leguminoseae - Papilionideae), espécie da flora arbórea do semi-árido, são pouco conhecidas. Assim, esta pesquisa teve por objetivos ilustrar e descrever as características morfológicas externas e internas dos frutos e sementes, fases de germinação, da plântula e planta.

\section{MATERIAL E MÉTODOS}

O presente trabalho foi realizado no Laboratório de Análise de Sementes do Departamento de Fitotecnia da Universidade Federal da Paraíba, em Areia. Os frutos e sementes foram coletados no solo, embaixo de árvores matrizes distribuídas em diferentes fragmentos florestais, no município de Areia - PB. Em seguida o material coletado foi transportado para o laboratório, onde os frutos e sementes mal conformadas e com injúrias foram eliminadas manualmente.

Para descrição morfológica de frutos e sementes examinaram-se 100 unidades, escolhidas aleatoriamente. Foram descritas e ilustradas as características morfológicas externas e internas de frutos e sementes, considerando os seguintes aspectos para caracterização do fruto: formato, cor; dimensões (comprimento, largura e espessura) e número de sementes por fruto. Para a descrição das sementes foram feitos cortes transversais e longitudinais com lâminas, sendo analisadas as seguintes variáveis: externas - coloração; dimensões (comprimento, largura e espessura), peso de 1000 sementes (Brasil, 1992), textura e consistência dos tegumentos, forma e dimensões (comprimento e largura) do hilo; internas - tipo de embrião (cotilédones, eixo hipocótiloradícula, plúmula), forma, tamanho, localização e presença ou ausência de endosperma.

As dimensões (comprimento, largura e espessura) dos frutos e das sementes foram obtidas, com paquímetro de $0,05 \mathrm{~mm}$ de precisão. As ilustrações foram feitas a olho nu ou com auxílio de estereomicroscópio, em escala 1:1 e, quando necessário, foram ampliadas. O método e os termos empregados foram baseados nos trabalhos de Font-Quer (1963); Radford et al. (1974); Ferri et al. (1981); Beltrati (1992); Vidal e Vidal (2000) e Ferreira et al. (2001a, b, c), Barroso et al. (2004) e Damião Filho e Môro (2005).

Para observação das características internas das sementes as mesmas foram escarificadas na extremidade oposta à micrópila com lixa d'água número 80 e imersas em água destilada por 24 horas, para facilitar os cortes. Cem sementes escarificadas foram semeadas em bandejas de polietileno com dimensões de 41 x 36 × 7,6 cm de comprimento, largura e altura, respectivamente, tendo como substrato vermiculita umedecida com água destilada quando necessário. As bandejas foram mantidas em ambiente de laboratório $\left( \pm 25^{\circ} \mathrm{C}\right)$, na presença de luz e as etapas da germinação foram observadas diariamente e ilustradas com auxílio de lupa de mesa. A germinação foi acompanhada desde o intumescimento da semente até a emissão dos protófilos de primeira ordem.

A plântula estabelecida foi considerada quando os protófilos de primeira ordem já estavam totalmente expandidos. Nesta fase, os caracteres descritos e ilustrados foram os mesmos sugeridos por Roderjan (1983): raiz (principal e secundária), colo, hipocótilo, cotilédone, epicótilo e protófilos de primeira ordem. Para as medições das plântulas e plantas utilizou-se régua graduada em centímetros $(\mathrm{cm})$. As ilustrações foram feitas a olho nu ou com auxílio de estéreo microscópio.

Para as dimensões (comprimento, largura e espessura) de frutos e sementes, bem como número médio de sementes por fruto, foi calculada a freqüência relativa (Fr), segundo Labouriau e Valadares (1976) e Labouriau (1983).

\section{RESULTADOS E DISCUSSÃO}

\section{Caracterização morfológica de frutos}

Os frutos possuem comprimento médio de $78,76 \mathrm{~mm}$ (variando de 41,08 a 138,26 mm), com predominância de frutos com comprimento entre 60 a $79 \mathrm{~mm}$; largura média de 13,42 mm (variando de 9,96 a 19,13mm) e predominância de 12-14 mm; espessura média de $9,82 \mathrm{~mm}$ (variando de 6,55 a 12,53 mm), cuja predominância foi de 8,94-14 mm (Figuras 1A-C). Apesar de pertencer ao mesmo gênero, os frutos de Erythrina speciosa Andrews são folículos oblongoelípticos, deiscentes, com oito a nove sementes por unidade, as quais têm características semelhantes aquelas de Erythrina speciosa, cujas diferenças se encontram apenas na forma (alongada-subquadrangular ou alongada reniforme), cor da fenda, do sulco hilar (castanho avermelhados) e do embrião (castanho-amarelado) (Groth e Andrade, 2002). Na espécie estudada os frutos são do tipo legume estipulado, glabro, polispérmico, de coloração marrom escura, com sementes vermelhas ou alaranjadas, duras, vernicosas, com mácula preta, variando de 1-4 por fruto (Figura 2 A-D). 

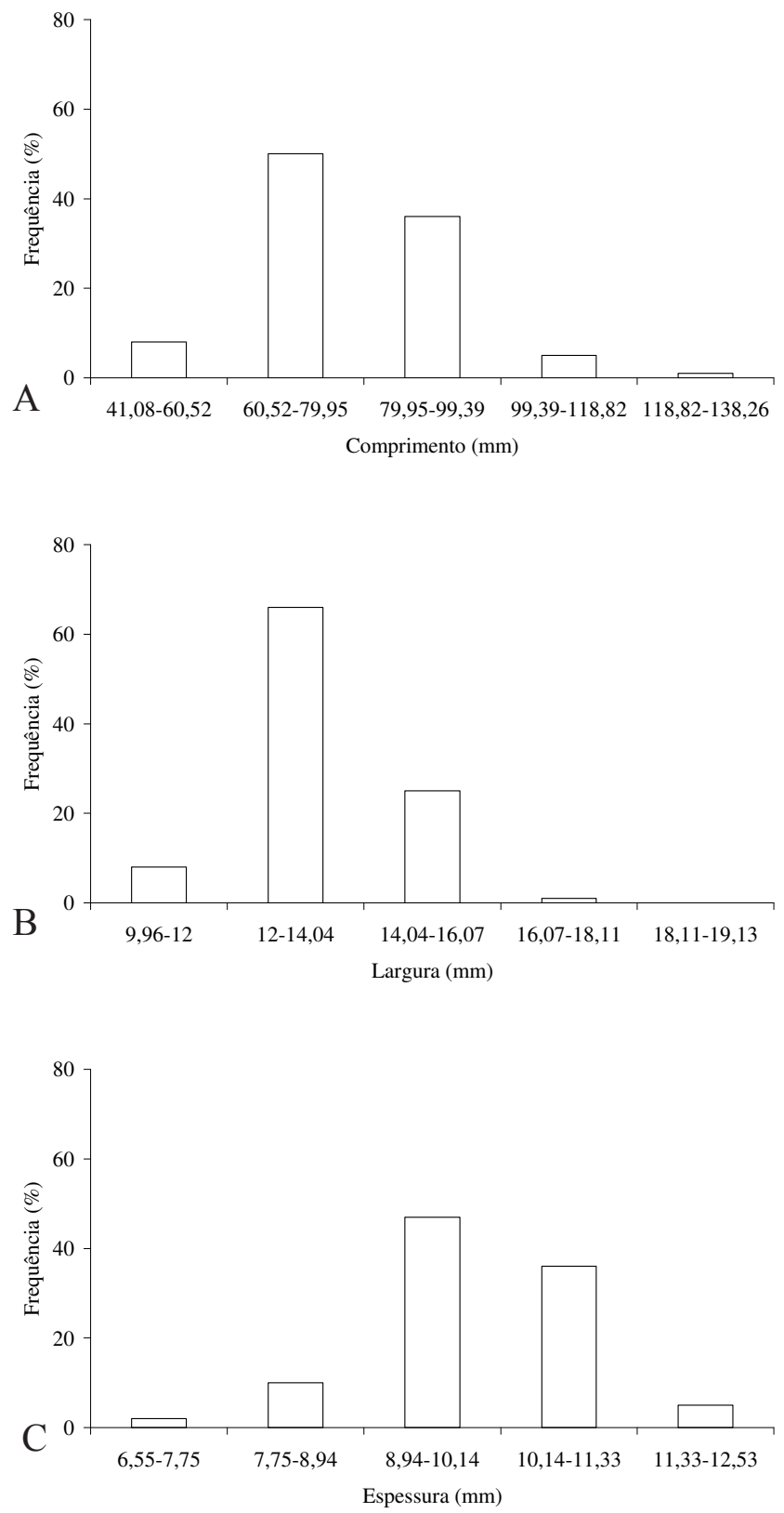

FIGURA 1. Distribuição da freqüência relativa do comprimento (A), largura (B) e espessura (C) de frutos de E. velutina.

De acordo com Barroso et al. (2004), o legume é originado de ovário súpero, unicarpelar, deiscente no ponto de junção das bordas do carpelo e na região dorsal, sobre a nervura mediana, formando duas valvas, característico apenas da família Leguminosae. A deiscência ocorre longitudinalmente, com abertura nas suturas ventral e dorsal, causando a separação das valvas, que se mantêm unidas na base.

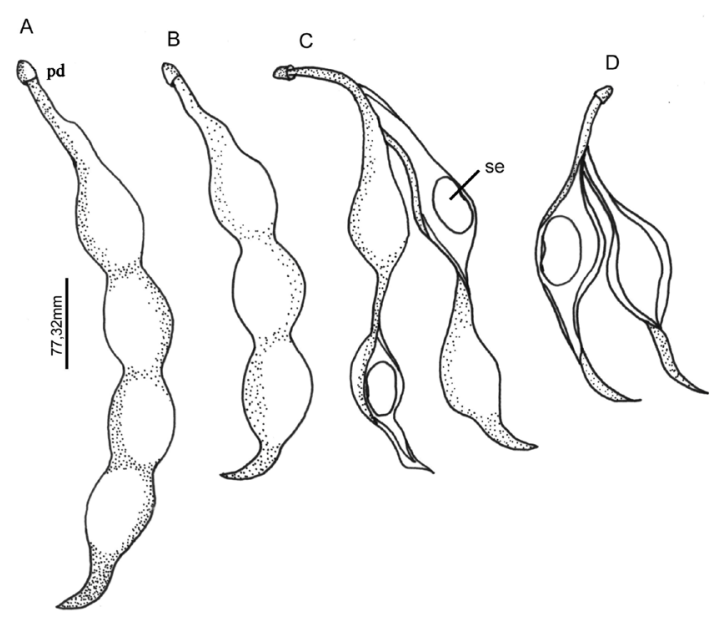

FIGURA 2. Aspectos morfológicos externos e internos do
fruto de Erythrina velutina: A-B - fechado;
B-C- aberto.

Legenda: se - semente; pd - pedicelo.

A variação morfológica dos tipos de frutos dentro da família Leguminosae foi estudada em 30 espécies por Oliveira (1997), das quais, 33,4\% apresentaram legumes e 23,3\% sâmaras. Outros tipos de frutos também foram encontrados: como o folículo em Swartzia langsdorfii Raddi, legume bacóide em Holocalyx balansae Mich., e craspédio em Mimosa caesalpiniaefolia Benth. Em espécies da família Leguminosae foram encontrados frutos como legume em Caesalpinia pyramidalis (Silva e Matos, 1998), Tephrosia candida DC. (Oliveira et al., 2000), Dimorphandra mollis (Ferreira et al., 2001c), Acacia polyphylla (Araújo Neto et al., 2002), legume drupóide para Dipteryx alata (Ferreira et al., 1998), Hymenaea stigonocarpa (Botelho et al., 2000), sâmara em Machaerium stipitatum (Donadio e Demattê, 2000b), Pterocarpus violaceus Vogel (Nakamura e Oliveira, 2005) e legume samaróide em Peltophorum dubium e Dalbergia nigra (Donadio e Demattê, 2000a), Cedrelinga catenaeformis e Dinizia excelsa (Melo e Varela, 2006).

\section{Caracterização morfológica de sementes}

A semente é estenospérmica (Beltrati, 1992), com comprimento médio de 12,54 $\mathrm{mm}$ (variando de 10,83 a $13,96 \mathrm{~mm}$ ), largura média de $8,15 \mathrm{~mm}$ (variando de 7,13 a 9,32 $\mathrm{mm}$ ), espessura média de 7,66 $\mathrm{mm}$ (variando de 6,54 a $8,64 \mathrm{~mm}$ ), predominando sementes com $12,08-12,71 ; 8,01$ 8,44 e 7,38-7,80 $\mathrm{mm}$ de comprimento, largura e espessura, respectivamente (Figuras 3A-C); formato alongado, reniforme, ápice arredondado e base arredondado-truncado; 
lóbulo radicular com ponta da radícula pouco protuberante lateralmente; lados incospicuamente convexos e sem pleurograma; bordo ventral côncavo, na porção mediana o hilo oblongo, levemente afundado, obscurecida por uma camada de tecido cortical esbranquiçado (Figura 4A-B), com cerca de 4,54 $\mathrm{mm}$ de comprimento por 2,10 $\mathrm{mm}$ de largura, variações de 3,63-5,40 e 1,08-27 mm, respectivamente (Figuras 5A-B) e no centro há uma estreita fenda hilar longitudinal de cor castanho-amarronzada (Figura 4B), que é típica da sub-família (Barroso et al., 2004) e também encontrada em sementes de Pterodon pubescens Benth. (Ferreira et al., 2001b); sulco hilar castanho que circunda o hilo. Na margem do hilo e orientado para a fenda hilar encontram-se presos restos do funículo esbranquiçado, em maior ou menor tamanho.
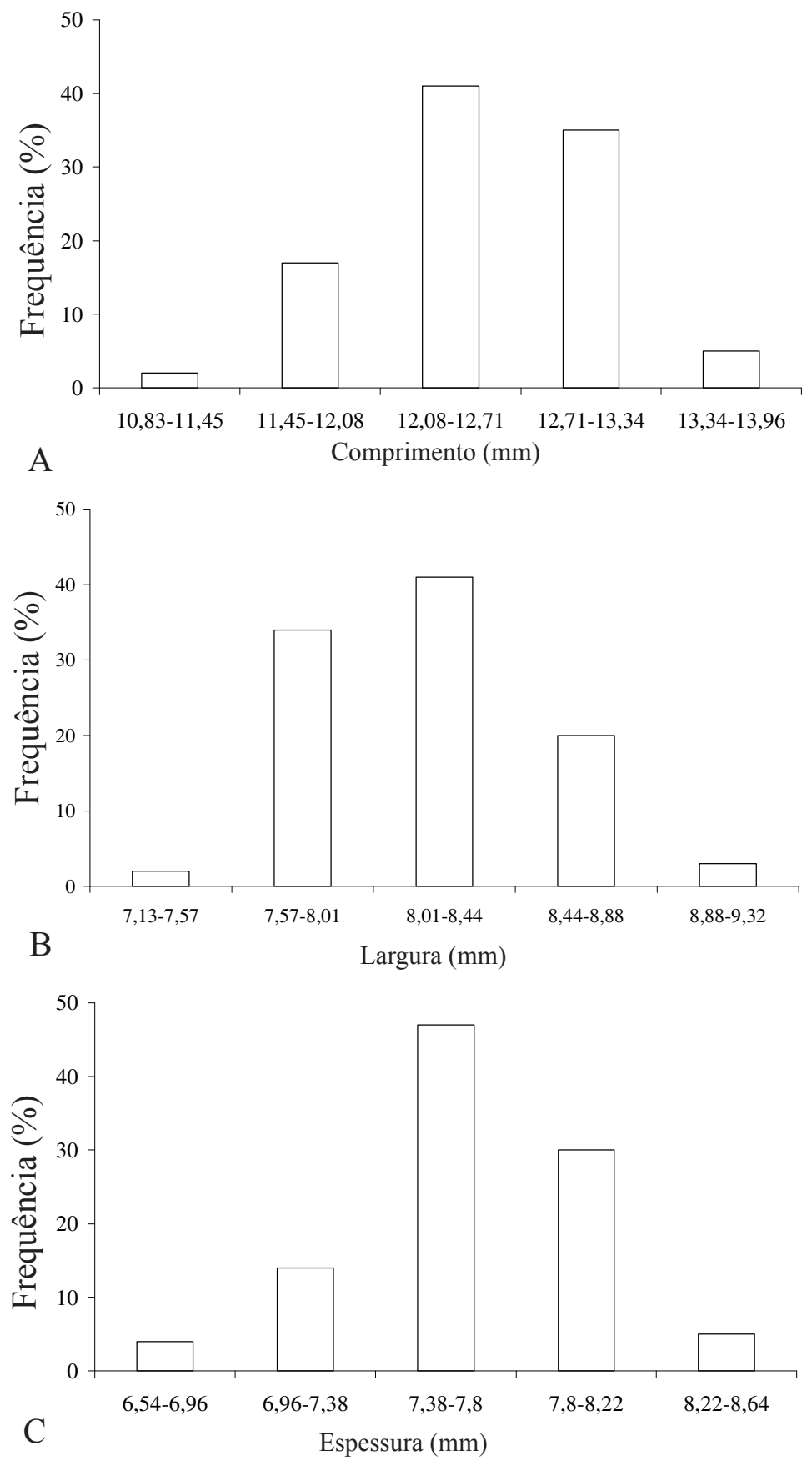

FIGURA 3. Distribuição da freqüência relativa do comprimento (A), largura (B) e espessura (C) de sementes de $E$. velutina. 

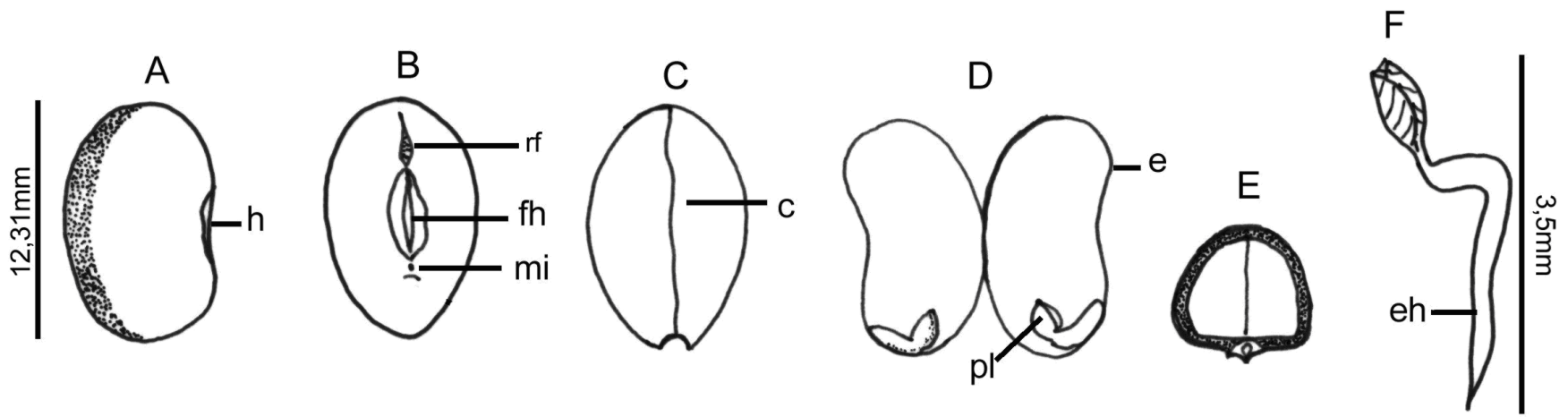

FIGURA 4. Aspectos morfológicos externos e internos da semente de Erythrina velutina: A - vista lateral; B - vista frontal; C - semente sem tegumento; D - semente aberta; E - corte transversal; F - Eixo hipocótiloradícula.

Legenda: h - hilo; rf - rafe; fh - fenda hilar; mi - micrópila; c - cotilédones; e - embrião; pl - plúmula; eh - eixo hipocótilo-radícula.
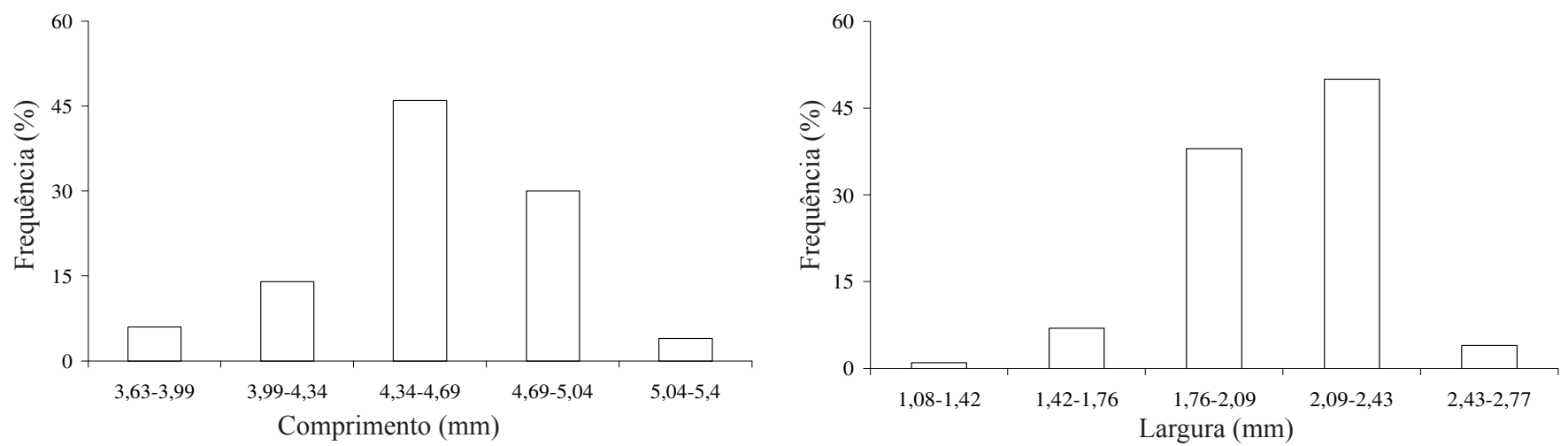

FIGURA 5. Distribuição da freqüência relativa do comprimento (A) e largura (B) do hilo de sementes de $E$. velutina.

Sementes reniformes também foram descritas em outras leguminosas, a exemplo de Tephrosia candida (Oliveira et al., 2000) e Machaerium stipitatum (Donadio e Demattê, 2000b), enquanto foram descritas em Caesalpinia pyramidalis e Zizyphus joazeiro (Silva e Matos, 1998), Tabebuia caraiba (Mart.) Bur. e Aspidosperma pyrifolium Mart. (Ferreira e Cunha, 2000), Peltophorum dubium (Donadio e Demattê, 2000a), Qualea grandiflora Mart. (Ferreira et al., 2001a), Amburana cearensis (Arr. Cam.) A.C. Smith (Cunha e Ferreira, 2003).

A micrópila é punctiforme; a rafe é pequena como uma listra alargada e elevada, mais ou menos visível dependendo do estádio de maturação da semente, a qual se localizada acima do hilo e oposta à micrópila (Figura 4B). O tegumento é cartáceo-coriáceo, glabro, superfície brilhante e lisa, coloração variando do vermelho ao alaranjado. Segundo Gunn (1981), geralmente a testa das sementes das espécies leguminosas apresenta cores marrom e preta. Deste modo, a cor vermelha a alaranjada pode ser considerada pouco freqüente assim como as cores ocre, creme ou branca quando presentes, sendo, portanto, um caráter bastante válido para identificação. Tegumento com coloração semelhante foi encontrado por Ferreira et al. (2001c) em sementes de Dimorphandra mollis, o qual variou de marrom-claro a vermelho-telha.

O embrião é axial curvado, reniforme, de coloração creme, constituído por cotilédones carnosos, grandes, esbranquiçados, assimétricos, plano-convexos, mucronados no ápice, que cobrem completamente o eixo hipocótiloradícula, grosso, curto, infletido com ponta divergente (Barroso et al., 2004), curva e deitada contra os bordos cotiledonares plano-convexos, incumbentes, reniformes, crassos, com ápice e base arredondadas; com plúmula parcialmente desenvolvida (Figura 4C-F). A semente madura é desprovida de endosperma, estando todo o material de reserva armazenado nos cotilédones, de forma que os mesmos ocupam todo o comprimento da semente.

A descrição do embrião está em conformidade com Barroso et al. (2004) quando relataram que o mesmo apresenta-se, geralmente, com cotilédones plano-convexos, 
variando de membranáceos a carnosos, sendo a região de inserção do eixo hipocótilo-radícula bem delimitada e de forma, em geral, cordado-sagitada ou apenas profundamente sagitada, sendo que o eixo, bastante curvo e infletido sobre os cotilédones, pode estar parcial ou totalmente alojado entre os mesmos, sendo que a plúmula apresenta-se de três formas distintas: rudimentar, quando os segmentos não são bem diferenciados, moderadamente desenvolvida quando apresentam segmentos em desenvolvimento e desenvolvidas quando os segmentos estão bem diferenciados em pinas.

Embriões axiais e sementes desprovidas de endospermas foram registrados para Dipteryx alata (Ferreira et al., 1998), Caesalpinia pyramidalis (Silva e Matos, 1998), Dalbergia nigra (Donadio e Demattê, 2000a) Machaerium stipitatum (Donadio e Demattê, 2000b), Acacia polyphylla (Araújo Neto et al., 2002), Pterodon pubescens (Ferreira et al., 2001b), Amburana cearensis (Cunha e Ferreira, 2003) e Hymenaea intermedia Ducke var. adenotricha (Ducke) Lee \& Lang. (Melo et al., 2004) e Pterocarpus violaceus (Nakamura e Oliveira, 2005).

\section{Morfologia da germinação e plântula}

A espécie apresentagerminaçãoepígea fanerocotiledonar, de acordo com a classificação de Duke e Polhill (1981). As primeiras manifestações de germinação iniciam-se pelo intumescimento da semente que aumenta de volume e, a partir do terceiro dia após a semeadura, ocorre a protrusão da radícula, mediante rompimento do tegumento no ápice da semente, sendo esta de coloração esbranquiçada com a coifa amarelada, nessa fase tem 2,0 cm de comprimento (Figura 6A); posteriormente adquire tonalidade creme e apresenta rápido desenvolvimento (Figura 6B). Cinco dias após a semeadura podem ser vistos, na radícula, pêlos simples, densos, translúcidos e em forma de agulhas. Os cotilédones mantêm-se envolvidos pelo tegumento, permanecendo assim por mais três ou quatro dias (Figura 6C), os quais, após a expansão são opostos, isófilos, carnosos, sésseis, levemente reniformes, cuja coloração evolui para verdeclaro e, posteriormente, para verde-escuro. No sexto dia após a semeadura o hipocótilo apresenta-se com $5,0 \mathrm{~cm}$ de comprimento, cilíndrico, levemente tortuoso próximo aos cotilédones, alongado e de cor verde-clara. Aos sete dias após a semeadura, os cotilédones começam a expandir-se até se abrirem totalmente, surgindo entre eles os protófilos de primeira ordem, com folhas simples e gema apical de coloração verde-escura. Nesta fase, a plântula tem 15,5 $\mathrm{cm}$ de comprimento (Figura 6D). No décimo quinto dia de semeadura a plântula encontra-se com $20 \mathrm{~cm}$ de comprimento, já possui o epicótilo, hipocótilo, raiz primária e os protófilos de primeira ordem totalmente expandidos, opostos e simples (Figura 6E). Na figura 7 pode ser observada a germinação das sementes de E. velutina, tendo início no terceiro dia e, atingindo $100 \%$ de germinação no nono dia após a semeadura.

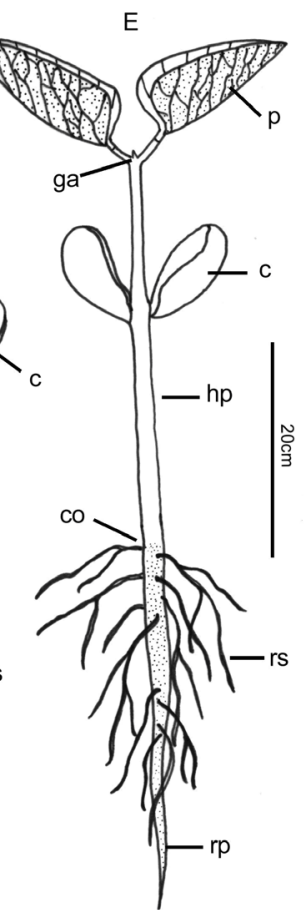

FIGURA 6. Fases da germinação e formação de plântula de Erythrina velutina.

Legenda: tg - tegumento; rp - raiz principal; rs - raiz secundária; co - coleto; pe - pelos; c - cotilédones; p - protófilo; ga - gema apical. 


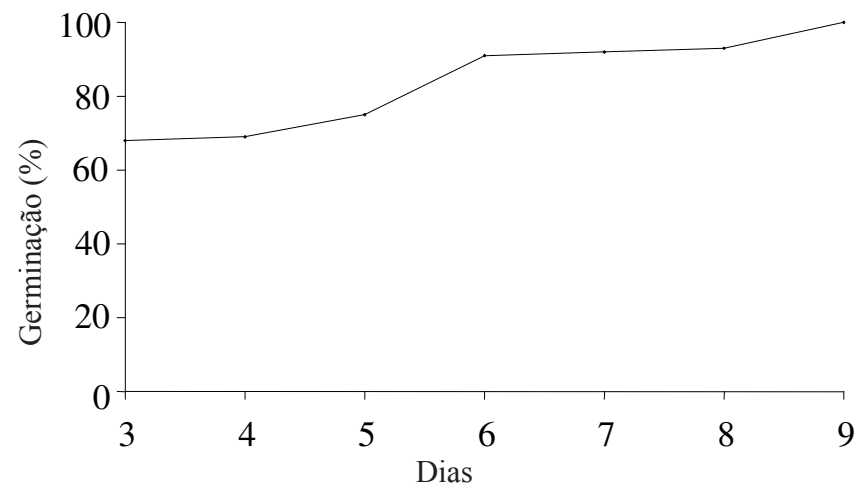

FIGURA 7. Curva de germinação de sementes de Erythrina velutina.

A germinação de sementes de algumas leguminosas como Hymenaea stigonocarpa, Dalbergia nigra e Peltophorum dubium, Machaerium stipitatum, Pterodon pubescens, Dimorphandra mollis, Acacia polyphylla, Hymenaea intermedia, Dalbergia nigra, Copaifera langsdorfii Desf. e Cedrelinga catenaeformis e Dinizia excelsa também é epígea fanerocotiledonar (Botelho et al., 2000; Donadio e Demattê, 2000a; b; Ferreira et al., 2001b; c; Araújo Neto et al., 2002; Melo et al., 2004; Andrade et al., 2006; Melo e Varela, 2006; Guerra et al., 2006), enquanto as de Amburana cearensis (Cunha e Ferreira, 2003) é do tipo semi-hipógea fanerocotiledonar.

\section{Morfologia da planta}

Aos 30 dias após a semeadura surgem os protófilos de segunda ordem, nesta fase a planta já tem acúleos. A partir de 50 dias, a planta tem, em média, $44,58 \mathrm{~cm}$ de comprimento (variando de 31 a $55,1 \mathrm{~mm}$ ), sistema radicular pivotante, longa, fina, sinuosa, caracterizada por um afinamento, com pêlos radicais desenvolvidos e raízes secundárias. $\mathrm{O}$ comprimento médio da raiz principal é de $14,33 \mathrm{~mm}$ (variando de 5 a 25 $\mathrm{mm}$ ), com coloração amarronzada, as raízes secundárias têm poucas ramificações laterais, curtas e finas, cujo coleto é cilíndrico, pouco nítido. O hipocótilo é longo, sub-herbáceo, cilíndrico, com comprimento médio de 7,84 $\mathrm{mm}$ (variando de 4,6 a 9,5 mm), enquanto o epicótilo é longo, fino, reto e liso, com a mesma coloração do hipocótilo e comprimento médio de $22,4 \mathrm{~mm}$ (variando de 15 a 33,5 mm). Os protófilos de segunda ordem são desenvolvidos, verde-escuros, opostos, compostos, trifoliolados, estipulados, peciolados, codiformes, bordas lisas, ápice agudo, base cordada e nervação reticulada (Figura 8A). Pulvínulo visível, verdes na mesma tonalidade da folha, cilíndricos, com tecido semelhante ao do epicótilo, com pêlos esparsos, simples, hialinos, curtos (Figura 8B). A plântula quando jovem apresenta heterofilia (Figura 8).

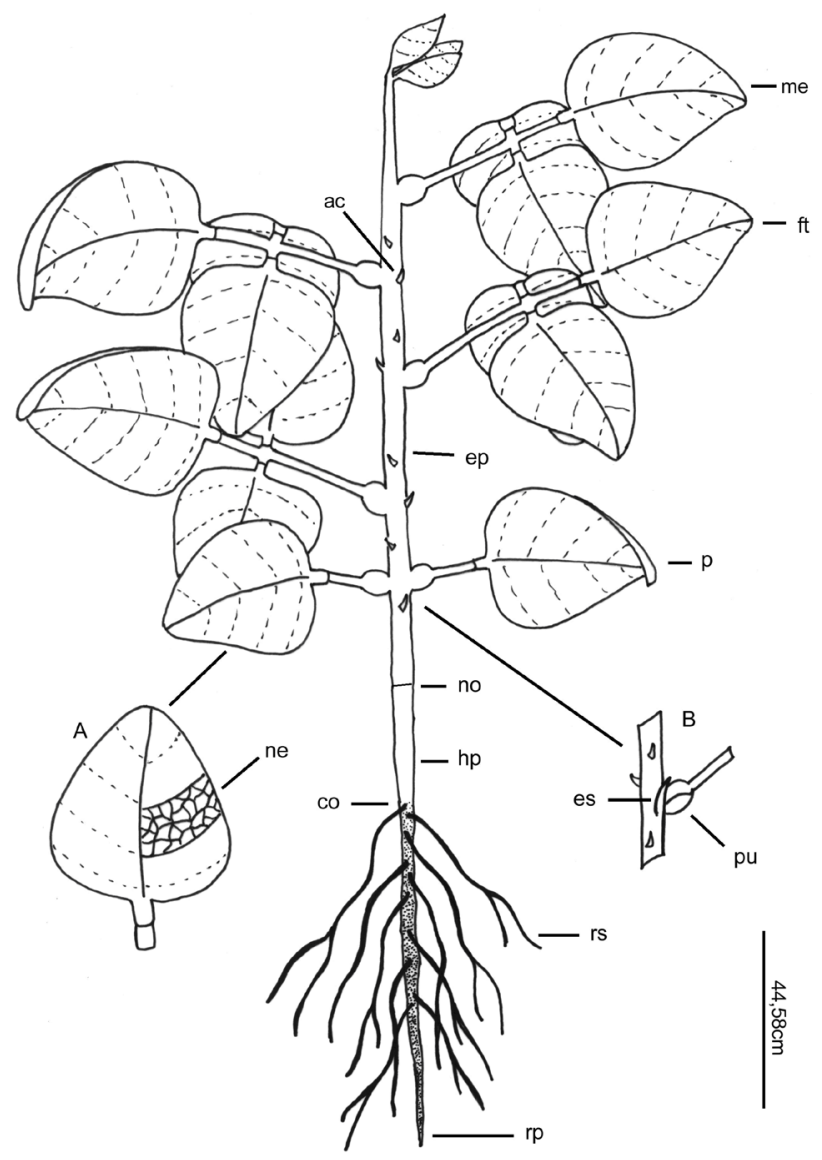

FIGURA 8. Aspecto morfológico do estádio de desenvolvimento da planta de Erythrina velutina aos 50 dias: A - detalhe da nervura na folha; B - detalhe do pulvínulo e estípula na base do pedicelo da folha.

Legenda: me - metáfilo; ac - acúleo; ft - folha trifoliolada; $\mathrm{p}$ - protófilo; ep - epicótilo; pu - pulvínulo; rp - raiz principal; rs - raiz secundária; ne nervura; ep - epicótilo; hp - hipocótilo; es - estípula; no - nó cotiledonar.

As plântulas de Erythrina speciosa Andrews apresenta-ram características semelhantes, a exemplo do sistema radicular (axial, com várias raízes secundárias e terciárias), hipocótilo curto, epicótilo de coloração verde clara, presença de acúleos, pulvínulo e nectário (Oliveira, 2001).

\section{CONCLUSÕES}

Os aspectos morfológicos do fruto, da semente, das fases de germinação, plântulas e planta de E. velutina são 
bastante homogêneos em todas as fases e confiáveis para a identificação da espécie;

A germinação das sementes de E. velutina é do tipo fanerocotiledonar, com início no terceiro dia e finalização no nono dia após a semeadura.

\section{AGRADECIMENTOS}

Ao CNPq pela concessão da bolsa de pesquisa e aos professores Genaro Viana Dornellas e Eduardo Machado dos Santos pelo auxílio na identificação das estruturas morfológicas.

\section{REFERÊNCIAS}

AMORIM, I.L. Morfologia de frutos, sementes, germinação, plântulas e mudas de espécies florestais da região de Lavras - MG. 1996. 127f. Dissertação (Mestrado em Engenharia Florestal) - Departamento de Silvicultura, Universidade Federal de Lavras, Lavras.

ANDRADE, A.C.S.; PEREIRA, T.S.; FERNANDES, M.J.; CRUZ, A.P.M.; CARVALHO, A.S.R. Substrato, temperatura de germinação e desenvolvimento pós-seminal de sementes de Dalbergia nigra. Pesquisa Agropecuária Brasileira, v.41, n.3, p.517-523, 2006.

ARAÚJO NETO, J.C.; AGUIAR, I.B.; FERREIRA, V.M.; PAULA, R.C. Caracterização morfológica de frutos e sementes e desenvolvimento pós-seminal de monjoleiro (Acacia polyphylla DC.). Revista Brasileira de Sementes, v.24, n.1, p.203-211, 2002.

ARAÚJO, S.S. MATOS, V.P. Morfologia de sementes e de plântulas de Cassia fistula L. Revista Árvore, v.15, n.13, p.217-230, 1991.

BARROSO, G.M. Curso de identificação de sementes. Pelotas: UFPel, 1978. 36p.

BARROSO, G.M.; MORIM, M.P.; PEIXOTO, A.L.; ICHASO, C.L.F. Frutos e sementes: morfologia aplicada à sistemática de dicotiledôneas. Viçosa: UFV, 2004. 443p.

BELTRATI, C.M. Morfologia e anatomia de sementes. Rio Claro: UNESP, Depto. de Botânica/Instituto de Biociências, 1992. 108p. (Apostila Curso de Pós-Graduação).

BOTELHO, S.A.; FERREIRA, R.A.; MALAVASI, M.M.; DAVIDE, A.C. Aspectos morfológicos de frutos, sementes, plântulas e mudas de jatobá-do-cerrado (Hymenaea stigonocarpa Mart. Ex Hayne) - Fabaceae. Revista Brasileira de Sementes, v.22, n.1, p.144-152, 2000.
BRASIL. Ministério da Agricultura e Reforma Agrária. Regras para análise de sementes. Brasília, DF: SNDA/ DNDV/CLAV, 1992. 365p.

CHAVES, M.M.F. Descrição morfológica de sementes, de plântulas e de mudas de 10 espécies arbóreas pioneiras, na microrregião de Viçosa, Minas Gerais. 1994. 108f. Dissertação (Mestrado em Ciências Florestais) - Universidade Federal de Viçosa, Viçosa.

CONER, E.J.H. The seeds of dicotyledons. Cambrige: University Press, 1976. v.1, 311p.

CUNHA, M.C.L.; FERREIRA, R.A. Aspectos morfológicos da semente e do desenvolvimento da planta jovem de Amburana cearensis (Arr. Cam.) A.C. Smith - Cumaru Leguminosae Papilionoideae. Revista Brasileira de Sementes, v. 25, n.2, p.89-96, 2003.

DAMIÃO FILHO, C.F.; MÔRO, F.V. Morfologia vegetal. 2.ed. Jaboticabal: FUNEP, 2005. 172p.

DONADIO, N.M.M.; DEMATTÊ, M.E.S.P. Morfologia de frutos, sementes, e plântulas de canafístula (Peltophorum dubium (Spreng.) Taub.) e jacarandá-da-Bahia (Dalbergia nigra (Vell.) Fr. All. ex Benth.) - Fabaceae. Revista Brasileira de Sementes, v.22, n.1, p.64-73, 2000a.

DONADIO, N.M.M.; DEMATTÊ, M.E.S.P. Caracterização morfológica de frutos, sementes e plântulas de sapuva (Machaerium stipitatum (DC.) Vog.) - Fabaceae. Revista Brasileira de Sementes, v.22, n.1, p.193-199, 2000 b.

DUKE, J.A.; POLHILL, R.M. Seedlings of Leguminosae. In: POLHILL, R.M.; RAVEN, P.H. Advances in legumes systematics. Kew: Royal Botanic Garden, 1981. p.941-949.

FERREIRA, R.A.; BOTELHO, S.A.; DAVIDE, A.C.; MALAVASI, M.M. Caracterização morfológica de fruto, semente, plântula e muda de Dipteryx alata Vogel - baru (Leguminosae Papilionoideae). Revista Cerne, v.4, n.1, p.73-87, 1998.

FERREIRA, R.A.; CUNHA, M.C.L. Aspectos morfológicos de sementes, plântulas e desenvolvimento da muda de craibeira (Tabebuia caraiba (Mart.) Bur.) - Bignoniaceae e pereiro (Aspidosperma pyrifolium Mart.) - Apocinaceae. Revista Brasileira de Sementes, v.22, n.1, p.134-143, 2000.

FERREIRA, R.A.; DAVIDE, A.C.; TONETTI, O.A.O. Morfologia de sementes e plântulas de pau-terra (Qualea grandilfora - Vochysiaceae). Revista Brasileira de Sementes, v.23, n.1, p.116-122, 2001a.

FERREIRA, R.A.; VIEIRA, M.G.G.C.; VON PINHO, E.V.R.; TONETTI, O.A.O. Morfologia da semente e de plântulas e avaliação da viabilidade da semente de sucupira- 
branca (Pterodon pubescens Benth. - Fabaceae) pelo teste de tetrazólio. Revista Brasileira de Sementes, v.23, n.1, p.108$115,2001 b$.

FERREIRA, R.A.; BOTELHO, S.A.; DAVIDE, A.C.; MALAVASI, M.M. Morfologia de frutos, sementes, plântulas e plantas jovens de Dimorphandra mollis Benth. faveira (Leguminosae-Caesalpinioideae). Revista Brasileira de Botânica, v.24, n.3, p.303-309, 2001c.

FERRI, M.G.; MENEZES, N.L.; MONTEIRO, W.R. Glossário ilustrado de botânica. São Paulo: Nobel, 1981. $197 \mathrm{p}$.

FONT-QUER, P. Dicionário de botânica. Barcelona: Labor, 1963. 1244p.

GROTH,D.; ANDRADE, R.N.B. Caracterização morfológica de unidades de dispersão de cinco espécies ornamentais. Revista Brasileira de Sementes, v.24, n.1, p.11-17, 2002.

GUERRA, M.E.C.; MEDEIROS FILHO, S.; GALLÃO, M.I. Morfologia de sementes, de plântulas e da germinação de Copaiferalangsdorfii Desf.(Leguminosae-Caesalpinioideae). Cerne, v.12, n.4, p.322-328, 2006.

GUNN, C.R. Seed collecting and identification. In: KOZLOWSKI, T.T. Seed biology. New York: Academic Press, 1972. v.1, p.1-20.

GUNN, C.R. Seed topography in the Fabaceae. Seed Science and Technology, Zürich, v.9, n.3, p.737-757, 1981.

KUNIYOSHI, Y.S. Morfologia da semente e da germinação de 25 espécies arbóreas de uma floresta com Araucaria. 1983. 233f. Dissertação (Mestrado em Engenharia Florestal) - Faculdade de Ciências Agrárias, Universidade Federal do Paraná, Curitiba.

LABORIAU, L.G. A germinação da semente. Washington: Secretaria Geral da OEA, 1983. 173p.

LABOURIAU, L.G.; VALADARES, M.B. On the physiology of seed of Calotropis procera. Anais da Academia Brasileira de Ciência, v.42, n.2, p.235-264, 1976.

LAWRENCE, G.H.M. Taxonomia das plantas vasculares. Lisboa: Fundação Caluste Gulbekian, 1973. v.1. 296p.

MELO, M.F.F.; VARELA, VP. Aspectos morfológicos de frutos, sementes, germinação e plântulas de duas espécies florestais da amazônia. I. Dinizia excelsa Ducke (angelimpedra). II Cedrelinga catenaeformis Ducke (cedrorana) Leguminosae: Mimosoideae. Revista Brasileira de Sementes, v.28, n.1, p.54-62, 2006.

MELO, M.G.G.; MENDONÇA, M.S.; MENDES, A.M.S. Análise morfológica de sementes, germinação e plântulas de jatobá (Hymenaea intermedia Ducke var. adenotricha (Ducke) Lee \& Lang.) (Leguminosae-caesalpinioideae). Acta Amazonica, v.34, n.1, p.9-14, 2004.

NAKAMURA, A.T.; OLIVEIRA, D.M.T. Morfoanatomia e ontogênese da sâmara de Pterocarpus violaceus Vogel (Fabaceae: Faboideae). Revista Brasileira de Botânica, v.28, n.2, p.375-387, 2005.

OLIVEIRA, A.N.; QUEIROZ, M.S.M.; RAMOS, M.B.P. Estudo morfológico de frutos e sementes de tefrósia (Tephrosia candida DC. - Papilionoideae) na Amazônia Central. Revista Brasileira de Sementes, v.22, n.2, p.193199, 2000.

OLIVEIRA, E.C. Morfologia de plântulas. In: AGUIAR, I.B.; PIÑARODRIGUES, F.C.M.; FIGLIOLIA, M.B. (Ed.). Sementes florestais tropicais. Brasília: ABRATES, 1993. p.175-214.

OLIVEIRA, D.M.T. Análise morfológica comparativa de frutos,sementes, plântulas e plantas jovens de 30 espécies arbóreas de Fabaceae ocorrentes no estado de São Paulo. 1997. 211f. Tese (Doutorado em Biologia Vegetal) - Instituto de Biociências do Campus de Rio Claro, Universidade Estadual Paulista, Rio Claro.

OLIVEIRA, D.M.T. Morfologia comparada de plântulas e plantas jovens de leguminosas arbóreas nativas: espécies de Phaseoleae, Sophoreae, Swartzieae e Tephrosieae. Revista Brasileira de Botânica, v.24, n.1, p.85-97, 2001.

PEREIRA, T.S. Bromelioideae (Bromeliaceae): morfologia do desenvolvimento pós-seminal de algumas espécies. Arquivo do Jardim Botânico do Rio de Janeiro, v.29, p.115154, 1988.

PINHEIRO, A.L. Estudos de características dendrológicas, anatômicas e taxonômicas de Meliaceae na microrregião de Viçosa. 1986. 192 f. Dissertação (Mestrado em Ciência Florestal) - Universidade Federal de Viçosa, Viçosa.

RADFORD, A.E.; DICKISON, W.C.; MASSEY, J.R.; BELL, C.R. Vascular plants sistematics. New York: Harper and Row, 1974. 877p.

RODERJAN, C.V. Morfologia do estádio juvenil de 24 espécies arbóreas de uma floresta com araucária, 1983. 148f. Dissertação (Mestrado em Engenharia Florestal) Universidade Federal do Paraná, Curitiba.

RUSSEL, P.G.; MUSIL, A.F. Las plantas deben dispersar sus semillas. In: USDA. Semillas. México: Continental, 1969. p.155-170.

SALLES, H.G. Expressão morfológica de sementes e plântulas I. Cephalocerus fluminensis (Miq) Britton e Rose 
(Cactaceae). Revista Brasileira de Sementes, v.9, n.1, p.7381, 1987.

SILVA, L.M.M.; MATOS, V.P. Morfologia de frutos, sementes e plântulas de catingueira (Caesalpinia pyramidalis Tul. - Caesalpinaceae) e de juazeiro (Zizyphus joazeiro Mart. - Rhamnanaceae). Revista Brasileira de Sementes, v.20, n.2, p.25-31-1998.

SILVA, L.M.M.; MATOS, V.P.; PEREIRA, D.D.; LIMA,
A.A. Morfologia de frutos, sementes e plântulas de Luetzelburgia auriculata Duck. (pau-serrote) e Pterogyne nitens Tul. (madeira-nova-do-brejo) Leguminosae. Revista Brasileira de Sementes, v.17, n.2, p.154-159, 1995.

SORIANO, S.; TORRES, R.B. Descrição de plântulas de árvores nativas. In: CONGRESSO DA SOCIEDADE BOTÂNICA DE SÃO PAULO, 9., 1992, Ilha Solteira. Anais... Campinas: SBSP, 1995. p.27-46.

VIDAL, W.N.; VIDAL, M.R.R. Botânica: organografia. 4.ed. Viçosa: UFV, 2000. 114p. 